\title{
Comparative analysis of airline financial and operational performances: A fuzzy AHP and TOPSIS integrated approach
}

\author{
Ki-Hwan Gabriel Bae ${ }^{a^{*}}$, Aman Gupta ${ }^{b}$ and Ronald Mau
}

a Department of Biomedical, Industrial and Systems Engineering, College of Engineering and Business, Gannon University, Erie, PA 16541, United States

${ }^{b}$ Department of Decision Sciences, College of Business, Embry-Riddle Aeronautical University - Worldwide, Daytona Beach, Florida, United States

${ }^{c}$ Department of Business Administration, College of Business, Embry-Riddle Aeronautical University - Worldwide, Daytona Beach, Florida, USA

\begin{tabular}{l}
\hline C H R O N I C L E \\
\hline Article history: \\
Received September 28, 2020 \\
Received in revised format: \\
December 29, 2020 \\
Accepted February 22021 \\
Available online \\
February 2, 2021 \\
\hline Keywords: \\
Fuzzy AHP \\
TOPSIS \\
Multi-Criteria Decision Making \\
(MCDM) \\
Airline \\
Financial performance
\end{tabular}
\begin{abstract}
A B S T R A C T
Already faced with tight competition and low profit margins, the airline industry is going through major changes in the wake of the current pandemic resulting in travel restrictions and slump demands, prompting airlines to curtail services and investments in every aspect of business. To that end, developing a comprehensive method of improving airline performance measures is crucial. However, this type of problem is complex to solve due to a large number of factors, requiring a systematic approach. It entails taking into account a multitude of conflicting, or sometimes interrelated criteria, hence becoming an inherently multiple criteria decision making problem. This study is aimed to assess the competitiveness of airlines and evaluate their financial and operational performances in relation to such criteria. We test FAHP, TOPSIS, and a hybrid method of combining FAHP and TOPSIS methods. In particular, regarding the hybrid method, FAHP is employed to determine the influential weights of criteria that are utilized in TOPSIS for preference values among alternatives. We demonstrate the applicability of the proposed methods to solving a MCDM problem of airline performance assessments using real data sets. Further, this study focuses on examining the relationship between financial and operational performance criteria, as well as gleaning insights for airlines to build an evaluation system that would aid in understanding their strength and weakness in the performance metrics. The computational experiment results of our hybrid FAHP-TOPSIS model support the efficacy of incorporating fuzzy values concerning influential weight criteria. By judiciously distributing criteria weights that are specific to the airline industry, our proposed model captures preference scores reflective of industry-related and concurrent measures. This modeling framework can help airlines better evaluate the systematic influential relation structure among criteria in critical financial and operational dimensions.
\end{abstract}

\section{Introduction}

Faced with tight competition, low profit margins, volatile oil price, and weak demands due to the recent coronavirus pandemic, airlines are struggling to survive by curtailing services and capital investments, and adopting different fuel hedging schemes. By operating at adequate levels, hence removing excess supply, airlines are attempting to restore profitability through high resource utilization, in addition to downsizing capacity. Under such circumstance, airlines are in greater need than ever to adapt their flight schedules in response to fast-changing and uncertain demand, while achieving a balance between demand and supply.

* Corresponding author. Tel.: +1-814-871-7045 Fax.: +1-814-871-7910

E-mail address: kbae04@vt.edu (K.-H. G. Bae)

(C) 2021 by the authors; licensee Growing Science, Canada.

doi: $10.5267 /$ j.dsl.2021.2.002 
Unprecedented capacity cuts, employee furloughs, cash constraints and government aid in the wake of the current pandemic resulted from travel restrictions as well as slump in demand among travelers. Given the severity of impact, demand will be slow to return to normal and airlines still be strapped for cash. Such a decline has led airlines to ground a large proportion of their fleet, resulting in many running into financial difficulties. Passenger revenue for airlines is estimated to plunge by $\$ 314$ billion in 2020, or a 55\% drop from 2019 levels, according to the International Air Transport Association (IATA, 2020). Consequently, airlines are also likely to have large debts to repay and would need to shore up their balance sheets, and need to reassess the size of operations in the face of a slow and difficult recovery that could take up to years to return to pre-COVID-19 traffic levels. We posit that, with the competitive nature of the airline industry, several mainline airline companies have similar financial structures, allowing us to compare them using mathematically driven techniques. The aim of this study is to assess the competitiveness of airlines and evaluate their financial performances in relation to various criteria. Typically, the improvement of airline financial and operational performances involves a complex decision-making process, requiring a systematic approach. Making such decisions entails taking into account a number of conflicting, or sometimes interrelated, criteria (Gomes et al., 2014). All of these elements make airline performance assessment an inherently multiple criteria decision making (MCDM) problem. Considering a number of financial measures available for airlines (see Section 2), this study adopts a Multi-Criteria Decision Making (MCDM) framework, to evaluate the airline performance using financial and operational data. We develop and apply ( $i$ ) Fuzzy Analytic Hierarchy Process (FAHP); (ii) Technique for Order Preference by Similarity to Ideal Solution (TOPSIS); and (iii) a hybrid method of combining Fuzzy AHP and TOPSIS methods to assess airline performances. In particular, regarding the hybrid method, a fuzzy approach is used to manage the vagueness of human decision (Patil \& Kant, 2014). Fuzzy AHP determines the influential weights of criteria that are utilized in TOPSIS for calculating preference values among alternatives.

The contribution of this paper is twofold. First, we test and demonstrate the applicability of our proposed methods to solving an MCDM problem of airline performance assessment using real comprehensive data sets. Second, our study focuses on examining the relationship between financial and operational criteria, as well as gleaning insights for airlines to build an evaluation system that would aid in understanding their strength and weakness of their performance.

The remainder of this paper is organized as follows: Section 2 reviews related literature on FAHP and TOPSIS practices, and explains the performance measures used in our study. Section 3 presents the actual methods and procedures of the proposed approach, and Sections 4-6 illustrate the results and discussion of the experiments tested on real data. Finally, concluding remarks are provided in Section 7.

\section{Background}

\subsection{Related literature}

Akkaya et al. (2015) presented a study on career field selection by industrial engineering students in multiple universities in Turkey using AHP and Multi-Objective Optimization by Ratio Analysis (MOORA). AHP was used to determine the significance of criteria and the sectors were determined using the fuzzy MOORA method. Jain et al. (2018) applied AHP and TOPSIS to the supplier selection process. The weights to criteria were assigned using AHP and the suppliers were ranked using AHP and TOPSIS. Limar et al. (2014) also applied multi-criteria decision analysis of supplier selection process to a company in the automotive production chain using FAHP and Fuzzy TOPSIS, and affirmed the benefit of Fuzzy TOPSIS. A multi-criteria decision making approach to evaluate sustainable supply chain management solutions was presented by Boutkhoum et al. (2018). The authors used an integrated approach using FAHP, TOPSIS, and Preference Ranking Organization Method for Enrichment Evaluations (PROMETHEE) to develop sustainable strategies for industrial organizations. A framework using FAHP and Fuzzy TOPSIS was proposed by Patil and Kant (2014) to identify and rank the solutions of Knowledge Management adoption in supply chains. They also developed the methodologies to propose ways to overcome barriers of Knowledge Management adoption. Pineda et al. (2018) presented a model combining data mining, Analytic Network Process (ANP), and VIKOR methods to assess airline performance. The authors used the dominance-based rough set approach to identify the factors and ANP to develop the evaluation system, and the VIKOR method was used to select alternative improvement goals. An application of MCDM in construction project management was developed by Prascevic and Prascevic (2017), utilizing trapezoidal fuzzy numbers to determine weights for Fuzzy AHP in conjunction with linear programming to determine local and global fuzzy weights of the alternatives. Roy and Dutta (2019) applied Fuzzy AHP and Fuzzy TOPSIS to study the factors that impact the operations of an electro discharge machining process, and asserted that none of the factors were highly significant. Samanlioglu et al. (2018) used Fuzzy AHP and Fuzzy TOPSIS to the personnel selection process in a Turkish dairy company's information technology department. Fuzzy AHP was applied to calculate the weights of the criteria and fuzzy TOPSIS was applied to rank the alternatives utilizing the weights obtained with fuzzy AHP. Similarly, Sirisawat and Kiatcharoenpol (2018) applied Fuzzy AHP and Fuzzy TOPSIS to rank the barriers to the implementation of Green Supply Chain Management. Venkatesh et al. (2019) applied Fuzzy AHP and Fuzzy TOPSIS to the supplier selection process in humanitarian operations. Feng and Wang (2000) applied similar methods to Taiwan's five major airlines using financial ratios, while Wang (2008) proposed grey relation analysis to cluster financial ratios and find representative indicators, and asserted the efficacy of using a fuzzy MCDM method in evaluation of the airline financial performance. However, no airline specific ratios were given in either paper. Garg (2016) developed a model for selecting strategic partners in the problem of making airline alliances by applying AHP 
for evaluation of the criteria and fuzzy TOPSIS for the partner decision of a strategic alliance. Barrosa and Wanke (2015) introduced a two-stage TOPSIS and neural network approach to analyze the efficiency of African airlines. The results showed that variables associated with airline networks size are most attributable, thus best indicators, to efficiency levels.

\subsection{Airline financial and operational metrics}

Our proposed model is tested on the airline financial data (D1-D4) obtained from the database of Mergent Online (2018) and on the operational data (D5) from the Bureau of Transportation Statistics (2018). The data set reports information about ten U.S. airline companies identified with indexed notations as follows: Alaska Air Group $\left(A_{1}\right)$, Allegiant Travel Company $\left(A_{2}\right)$, American Airlines Group $\left(A_{3}\right)$, Delta Air Lines $\left(A_{4}\right)$, Hawaiian Holdings $\left(A_{5}\right)$, JetBlue Airways $\left(A_{6}\right)$, SkyWest $\left(A_{7}\right)$, Southwest Airlines $\left(A_{8}\right)$, Spirit Airlines $\left(A_{9}\right)$, and United Continental Holdings $\left(A_{10}\right)$. Each airline company is evaluated by 16 financial metrics denoted as P1-P16 in Table 1, however the inclusion of all metrics in the analysis is overlapped and not practical. To obviate evaluating on similar financial ratios redundantly, financial ratios are partitioned into several clusters such as financial structure data, liquidity, turnover, profitability, and airline operational measures denoted as D1, D2, D3, D4, and D5, respectively. We select a representative indicator from each cluster as an evaluation criterion in the experiments of Sections 4-6.

Table 1

Airline financial and operational criteria and categorization.

\begin{tabular}{ccc}
\hline D1 & P1 & (TL/TA) Debt Ratio \\
(Financial Structure) & P2 & (TE/TA) Equity Ratio \\
& Total Debt to Equity \\
\hline \multirow{2}{*}{ D2 } & P3 & Current Ratio \\
(Liquidity) & P5 & Quick Ratio \\
\hline \multirow{2}{*}{ D3 } & P6 & Time Interest Earned \\
\hline (Turnover) & P7 & (TR/TA) Total Asset Turnover \\
& P8 & (TR/PPE) PPE Turnover \\
\hline \multirow{2}{*}{ D4 } & P9 & (TR/CA) Current Asset Turnover \\
\hline (Profitability) & P10 & Gross Margin Percentage \\
& P11 & Return on Equity Percentage (Net) \\
D5 & P12 & Return on Assets Percentage (Net) \\
\hline \multirow{2}{*}{ (Airline Operational Measures) } & P13 & Load Factor Percentage \\
& P14 & Revenue per Available Seat Mile \\
& P15 & Cost per Available Seat Mile \\
\end{tabular}

Publicly trading airlines disclose their financial statements (to shareholders) periodically to describe operations and financial conditions. As such, financial ratios are reported in general from public financial statements to assess various financial aspects containing profitability, leverage, liquidity, rate of returns, valuation, and others. The ratios are broadly used across many industries and include financial structure, liquidity, turnover, and profitability ratios. Additionally, there exist performance ratios that are unique to the airline industry. To overcome a limitation of using a single metric alone, we consider several ratios that provide evaluations from multiple sources. This is part of our motivation to adopt an MCDM approach and develop aforementioned ranking models to analyze airline performance. Next, we discuss in detail individual financial performance indicators including financial structure, liquidity and leverage, turnover, and profitability, as well as airline operational measures including load factor, revenue per available seat mile, cost per available seat mile, and passenger yield. Financial structure ratios provide information related to how an organization is financed. Firms can finance their operations by issuing bonds (i.e., debt financing) or shares (i.e., equity financing). The ratios explain whether a firm is predominantly financed with debt or equity. Debt financing can result in financial distress if a firm is not able to make interest payments. However, financing with debt versus equity is a financial structure choice and there are times when levering up by taking on more debt may be the correct decision. Debt ratio is defined as total liabilities divided by total assets, and interpreted as what percentage of the firm is financed with debt. Equity ratio is the firm's equity divided by total assets, and considered as the percentage of a firm that is financed with equity. It should be noted the debt ratio and equity ratio are related and should sum to one as each represents the amount the firm is financed by one of two options. Total debt to equity ratio is calculated by taking all debt obligations and dividing by the firm's equity. A ratio of greater than one would indicate the portion assets provided by creditors is greater than equity holders; conversely, a ratio of less than one would indicate the portion of assets provided by equity holders is greater than creditors.

Liquidity ratios and leverage ratios provide information related to a firm's ability to pay their obligations without undue stress. Current ratio is calculated by dividing current assets by current liabilities. Current assets refer to ones that can be converted to cash within a year, and include cash, accounts receivables, and inventory. Similarly, current liabilities represent amounts to be paid to creditors. The current ratio is a measure of short-term liquidity and a higher ratio indicates the ability for a firm to meet its short term obligations. Quick ratio is similar to the current ratio but excludes two step assets or less liquid short-term assets. For most forms, it would be inventory that needs to be sold before cash is received. Times interest earned (TIE), sometimes referred to as cushion, is a long term solvency measure calculated as earnings before interest and 
tax (EBIT) divided by interest. TIE measures how well a firm has its interest obligations covered. A higher ratio would be indicative of more financial cushion to meet its debt obligations.

Turnover ratios provide information related to the firm's activity. The ratios provide insights into how efficiently a firm is utilizing assets to generate revenues. Total asset turnover is defined as total revenues divided by total assets. The measure indicates how many times the assets are turned to generate the firm's revenues. Total PPE (property plant and equipment) turnover is similar to total asset turnover but the denominator consists of property plant and equipment only, thus often referred to as fixed asset turnover. Firms making substantial capital outlays can be evaluated more closely using this ratio as it indicates how efficiently the firm is using its large capital investments to generate revenues. Current asset turnover is defined as revenues divided by current assets. The ratio reflects the number of times current assets turnover a year. This ratio is an indicator of the efficiency with which a company is deploying assets to generate revenues. Profitability ratios provide insights into the profitability of a firm. However, in practice there are various ways to consider profitability. Some profitability ratios are balance sheet-based and others are income statement-based, and each can shed a different view on how the firm is performing. Gross margin is the total sales revenues less the cost of goods divided by total sales revenues. This metric represents the percentage of the firm's revenues retained on each dollar of sales after accounting for the cost of goods sold. A higher percentage would be a sign of better firm performance. Return on equity (ROE) is the amount of net income divided by the owner's equity. ROE is a profitability measure indicating how much profit the firm generates with the owner's (or shareholder's) investment. Return on assets is calculated by dividing net income by total assets. Also known as return on investment, compared to ROE, this ratio utilizes all business assets. The airline operational ratios including load factor, revenue per available seat mile (RASM), cost per available seat mile (CASM), and passenger yield are performance measures widely used in the airline industry. Load factor measures the utilization of the seats available to an airline. For a single flight, load factor is calculated by taking the number of occupied seats divided by the number of seats available. For an airline, all flights are aggregated and an overall load factor is assessed, and the metric represents how effectively the airline fills seats to generate revenues. Revenue per available seat mile (RASM) is defined by dividing operating revenue by available seat miles. Typically, a higher RASM translates into more efficient use of airline capacity and likely higher profitability. Costs per available seat mile (CASM) is similar to RASM except the numerator of the ratio is the costs for an airline. The ratio refers to the cost of operating each seat offered and is another method for evaluating performance efficiency. A lower CASM would indicate lower costs for airline operations. Passenger yield is calculated by dividing passenger revenues by revenue passenger miles, and the metric represents the average fare per passenger per mile.

\section{Methods}

\subsection{Fuzzy analytic hierarchy process}

FAHP modeling analyzes criteria and alternative choices by utilizing pairwise comparisons between a criterion and an alternative, similar to AHP analysis (Saaty, 2012; Brunelli, 2014). However, single-value pairwise comparisons do not account for the indefinite subjectiveness of a decision maker. FAHP considers such subjective elements with a range of values via a fuzzy logic approach in a decision making process (Ayhan, 2013). Fuzzy logic employs values between 0 and 1 that represent a state of being completely false and completely true, and assumes that linguistic terms are rendered with triangular fuzzy numbers limited in the interval of $[0,1]$. The assignment of multiple values to a pairwise comparison scale in this study follows the triangular scale on the fuzzy development of AHP by van Laarhoven and Pedrycz (1983). Next, we lay out the theoretical procedure step by step incorporated in our FAHP analysis. The single-value comparison is based upon the scale developed by Saaty (2012), while the triangular scale and associated procedures follows the works of Buckley (1985) and Ayhan (2013).

Step A.1: A decision maker compares a pair of criteria (or a pair of alternatives in relation to a criterion) according to the Saaty scale, which is a type of vocabulary-based scale, and convert the values to the associated range of fuzzy logic values in Table T1 (see the table in Appendix). Without loss of generality, we focus on the procedure of comparing criteria; alternatives can be compared in a similar fashion. For example, if Criterion 1 is strongly more important than Criterion 2 , then $(6,7,8)$ can be assigned as a comparative range of values. The inverse operation is then applied for Criterion 2 in comparison to Criterion 1, and a comparative range of values $(1 / 8,1 / 7,1 / 6)$ is assigned. That is, Criterion 2 is considered strongly less important than Criterion 1 . The pairwise comparisons made by each decision maker are assembled into the matrix $A$ defined in Equation (1). $\overrightarrow{d_{\imath \jmath}}$ represents the set of fuzzy range values associated with a decision maker's assessment of the relation between the $i^{\text {th }}$ and the $j^{\text {th }}$ criteria. For the example above, $\overrightarrow{d_{12}}=(6,7,8)$.

$$
A=\left[\begin{array}{cccl}
\overrightarrow{d_{11}} & \overrightarrow{d_{12}} & \cdots & \overrightarrow{d_{1 n}} \\
\overrightarrow{d_{21}} & \overrightarrow{d_{22}} & \cdots & \overrightarrow{d_{2 n}} \\
\vdots & \vdots & \cdots & \vdots \\
\overrightarrow{d_{n 1}} & \overrightarrow{d_{n 2}} & \cdots & \overrightarrow{d_{n n}}
\end{array}\right]
$$


Step A.2: The geometric mean is calculated by Eq. (2). $\vec{r}_{l}$ represents the triangular values, i.e., each criterion will have three geometric averages in accordance with the set of three values used for the comparisons (Buckley, 1985).

$$
\vec{r}_{\imath}=\left(\prod_{j=1}^{n} \overrightarrow{d_{\imath \jmath}}\right)^{1 / n} \forall i
$$

Step A.3: Calculate the fuzzy logic weight for each criterion using the following three steps leading to Eq. (3).

Step A.3.1: Sum $\vec{r}_{l}$ values across $i$ per each of the triangular components, resulting in three summation operations. Step A.3.2: Subject three summations to being raised to the power of -1 , and sort the resulting values from smallest to largest.

Step A.3.3: Find the fuzzy logic weight of each criterion, $\vec{w}_{l}$ using Eq. (3), where $l w_{i}, m w_{i}$, and $u w_{i}$ comprise the associated fuzzy weights for $i$.

$$
\overrightarrow{w_{l}}=\overrightarrow{r_{l}} \otimes\left(\overrightarrow{r_{1}} \oplus \overrightarrow{r_{2}} \oplus \ldots \oplus \overrightarrow{r_{n}}\right)^{-1}=\left(l w_{i}, m w_{i}, u w_{i}\right)
$$

where $\otimes$ and $\bigoplus$ are mathematical operators of the extended multiplication and addition on fuzzy numbers.

Step A.4: The centre of area method by Chou and Chang (2008) is applied in Eq. (4) to convert the triangular components for each criterion into a singular value denoted $M_{i}$.

$$
M_{i}=\frac{l w_{i}+m w_{i}+u w_{i}}{3}
$$

Step A.5: Normalize $M_{i}$ values by Eq. (5) in order to develop final normalized weights $N_{i}$ for each criterion. The criterion with the largest weight has the most influence on the final outcome. Similarly, an alternative with the highest score can be found and regarded as the most preferred option in relation to a specific criterion.

$$
N_{i}=\frac{M_{i}}{\sum_{i=1}^{n} M_{i}}
$$

Step A.6: Multiply each alternative score with the associated criteria weight in order to find the finalized weights which in turn show the most preferred alternative options.

\subsection{Technique of order preference by similarity to ideal solution}

TOPSIS modeling analyzes criteria and alternative choices by developing scores for each alternative to each criterion. Two alternatives are set up in TOPSIS: an ideal alternative constructed by selecting the best possible values for all attributes considered, and a negative ideal alternative constructed by selecting the worst alternative options for all attributes considered. TOPSIS makes use of both alternatives to facilitate a selection of an alternative option that is closest to the ideal solution and farthest from the negative ideal solution. This section details a step-by-step theoretical procedure by Duffuaa (2009). TOPSIS incorporates $m$ alternatives (indexed by $i \in I$ ) and $n$ criteria (indexed by $j \in J^{+}, J^{-}$). $J^{+}$is the set of positive criteria considered in the ideal alternative, and $J^{-}$is the set of negative criteria considered in the negative ideal alternative. A subjective score for option $i$ to criterion $j$ is denoted as $x_{i j}$ and assessed for each pair in $m$ by $n$ matrix denoted $X$.

Step B.1: Construct a normalized decision matrix using Equation (6). In this equation, $r_{i j}$ represents the normalized score of alternative $i$ to criterion $j$.

$$
r_{i j}=\frac{x_{i j}}{\sum_{i}^{m} x_{i j}^{2}}, \quad \forall i, j
$$

Step B.2: Construct a weighted normalized decision matrix using Eq. (7). A set of subjective weights for each criterion, denoted $w_{j}$, is multiplied by $v_{i j}$ represents the weighted normalized score of alternative $i$ for criterion $j$.

$$
v_{i j}=w_{j} \times r_{i j}, \quad \forall i, j
$$

Step B.3: Determine the ideal solution $A^{+}$and the negative ideal solution $A^{-}$. The ideal solution is based on selecting the alternative option value that has the best performance in each criterion, whereas the negative ideal solution is based on selecting the alternative value that has the worst performance in each criterion. The ideal and negative ideal solutions are presented formally in Equations (8) and (9), respectively. In Eq. (8), $v_{j}{ }^{+}$represents the highest value among the alternative options for each specific criterion $j$. Likewise, in Eq. (9), $v_{j}{ }^{-}$represents the lowest value among the options for each specific criterion $j$.

$$
\begin{aligned}
& A^{+}=\left\{v_{1}{ }^{+}, \ldots, v_{n}{ }^{+}\right\}, \text {where } \\
& v_{j}^{*}=\left\{\max \left(v_{i j}\right) \text { if } j \in J^{+} ; \min \left(v_{i j}\right) \text { if } j \in J^{-}\right\}, \quad \forall i \\
& A^{-}=\left\{v_{1}{ }^{-}, \ldots, v_{n}{ }^{-}\right\}, \text {where } \\
& \qquad v_{j}^{\prime}=\left\{\min \left(v_{i j}\right) \text { if } j \in J^{+} ; \max \left(v_{i j}\right) \text { if } j \in J^{-}\right\}, \quad \forall i
\end{aligned}
$$

Step B.4: Calculate the separation measures for each alternative option value to a given criterion. This includes measuring the separation of each alternative value from the ideal criterion value, denoted $S_{i}^{+}$in Equation (10), as well as the separation of each alternative value from the negative ideal criterion value, denoted $S_{i}^{-}$in Eq. (11). 


$$
\begin{aligned}
S_{i}^{+} & =\left[\sum_{j}^{n}\left(v_{j}^{+}-v_{i j}\right)^{2}\right]^{1 / 2}, \quad \forall i \\
S_{i}^{-} & =\left[\sum_{j}^{n}\left(v_{j}^{-}-v_{i j}\right)^{2}\right]^{1 / 2}, \quad \forall i
\end{aligned}
$$

Step B.5: Find the relative closeness to the ideal solution, denoted $C_{i}^{*}$, using Equation (12).

$C_{i}^{*}=S_{i}^{-} /\left(S_{i}^{+}+S_{i}^{-}\right), \quad \forall i$

Step B.6: Rank alternatives by $C_{i}^{*}$ values. The largest value corresponds to the most preferred alternative option, whereas the smallest value is associated with the least preferred option.

\subsection{A hybrid model of FAHP and TOPSIS}

The direct input of criteria weights or alternative scores used in the prior FAHP and TOPSIS procedure alone assume subjective assessments of a single decision maker. Furthermore, the TOPSIS method implicates some limitations on conveying the vagueness of data under fuzzy environment (Kannan et al., 2014). In order to reduce the effect of such subjective elements, we develop a two-stage process where FAHP is first applied to develop criteria weights that are subsequently used in the TOPSIS analysis within a combined MCDM modeling framework (Ertuğrul \& Karakaşoğlu, 2009). Specifically, an algorithmic procedure for the first stage of using FAHP extracts criteria weights from Steps A.1-A.5 and substitute them for $w_{j}$ in Step B.2, and then sequences the remaining Steps B.3-B.6.

\section{Experiments of FAHP application}

\subsection{Evaluating financial performance by FAHP}

In this section, we design experiments to test the application of FAHP to the MCDM airline financial performance and competitiveness. The first experiment considers pairwise comparisons between the most important criterion selected from each of the four categories (D1, D2, D3, and D4) and ten alternatives representing airlines in relation to each selected criterion. The criteria for this experiment are selected in consultation of airline experts; debt ratio (P1), time interest earned (P6), total asset turnover (P7), and gross margin percentage (P10).

[Step A.1] Pairwise comparisons between each examined criterion are made according to the Saaty scale, then converted to the fuzzy logic triangular scale as in Tables T2 and T3.

[Step A.2] The geometric mean of each criterion is calculated according to Eq. (4). Table T4 presents the results for this step.

[Steps A.3.1 - A.3.3] The fuzzy logic triangular weights for each criterion were calculated in Tables T5 and T6 using Equation (5).

[Steps A.4 and A.5] The centre of area method is applied to the fuzzy weights using Equation (6) and subsequently normalized using Equation (7) to find the criteria that influenced the final outcome the most. According to Table T7, Criterion P10 has the most impact on the final decision.

[Step A.6] Repeat Steps A.1-A.5 for alternative comparisons in relation to the four criteria (P1, P6, P7, and P10). A ranking method based on value ranges is utilized to expedite the pairwise comparison and ranking of each alternative with respect to the four criteria. The criteria weights and alternative scores per each criterion, and the multiplication of each criterion weight by associated alternative scores are shown in Tables T8 and T9, respectively.

\subsection{Financial and operational performance results by FAHP}

In this section, we compare the results of five experiments conducted using FAHP in regard to the airline financial and operational performance evaluation. Table 2 shows that the first experiment takes into account the most important set of criteria selected from the four categories D1, D2, D3, and D4 of financial performance. For the remaining experiments, the four criteria of load factor (P13), RASM (P14), CASM (P15), and passenger yield (P16) under the category D5 are incrementally included one at a time in order to understand the impact of a particular operational performance on the overall ranking among the airlines under consideration. Further, each criteria variable in D5 is added sequentially in order of importance based upon the subjective preference.

Table 2

\begin{tabular}{cccccccc} 
Experiment designs & \multicolumn{1}{c}{} & & & \\
\hline Category & D1 & D2 & D3 & D4 & D5 & P14 \\
\hline Criterion & P1 & P6 & P7 & P10 & P13 & P15 \\
\hline Experiment 1 & $\sqrt{ }$ & $\sqrt{ }$ & $\sqrt{ }$ & $\sqrt{ }$ & & $\sqrt{ }$ \\
Experiment 2 & $\sqrt{ }$ & $\sqrt{ }$ & $\sqrt{ }$ & $\sqrt{ }$ & $\sqrt{ }$ \\
Experiment 3 & $\sqrt{ }$ & $\sqrt{ }$ & $\sqrt{ }$ & $\sqrt{ }$ & $\sqrt{ }$ \\
Experiment 4 & $\sqrt{ }$ & $\sqrt{ }$ & $\sqrt{ }$ & $\sqrt{ }$ & $\sqrt{ }$ \\
Experiment 5 & $\sqrt{ }$ & $\sqrt{ }$ & $\sqrt{ }$ & $\sqrt{ }$ & $\sqrt{ }$ & $\sqrt{ }$ \\
\hline
\end{tabular}




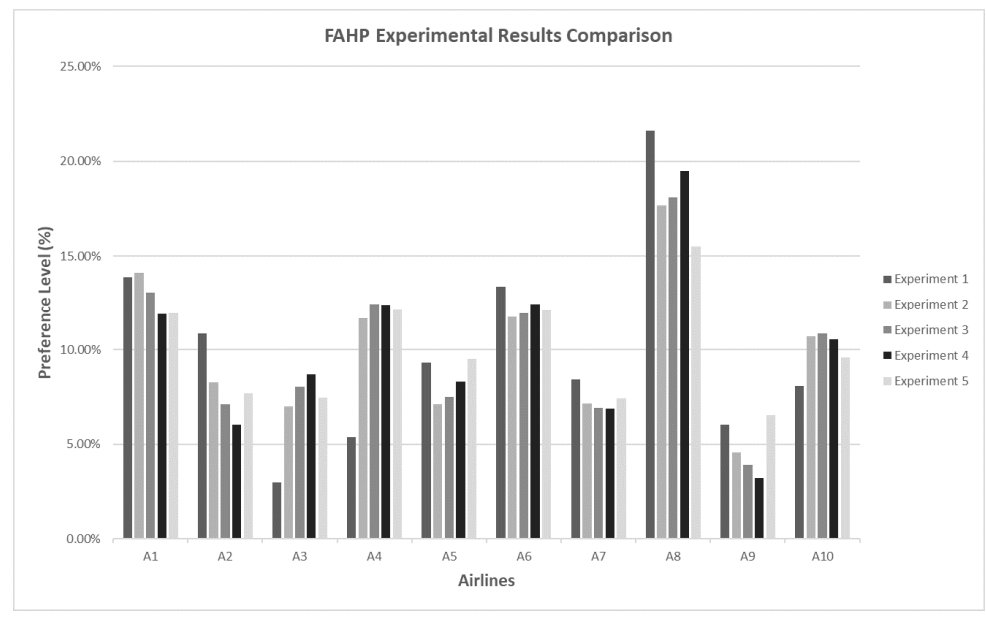

Fig. 1. FAHP experimental results.

Fig. 1 presents the corresponding results of using FAHP for the MCDM analysis. $\mathrm{A}_{8}$ performs best across all experiments, and $A_{9}$ is consistently the least preferred alternative across multiple experiments. Legacy carriers such as $A_{3}, A_{4}$, and $A_{10}$ see a trend of significant increases in preference level due to the inclusion of airline operational measures. For instance, in the first experiment, $\mathrm{A}_{4}$ underperforms when considering only financial categories (D1, D2, D3, and D4), but excels in the criteria with an addition of D5. This indicates that $\mathrm{A}_{4}$ becomes more competitive and preferred with the inclusion of airline operational performances. We note that the top four alternatives $\left(\mathrm{A}_{1}, \mathrm{~A}_{4}, \mathrm{~A}_{6}\right.$, and $\left.\mathrm{A}_{8}\right)$ account for more than $50 \%$ of the total preference level in any of five experiments. Moreover, the average decreases by $5.5 \%$ in range and by $1.4 \%$ in standard deviation from Experiment 1 to Experiments 2-5 suggests that the preference percentages become more evenly distributed as more criteria are accounted for by the FAHP model.

\section{Experiments of TOPSIS application}

\subsection{Evaluating financial performance by TOPSIS}

Similar to the FAHP analysis, five experiments are designed to test the application of TOPSIS to airline financial and operational performances. The experiment structure is the same as the one used for the FAHP application in Section 4.1; that is, TOPSIS is used to assess the preferences among alternatives based on the criteria P1, P6, P7, and P10. The criteria weights and alternative scores for $x_{i j}$ in $X$ are presented in Table T10. A ranking method based on value ranges is used to assign alternative scores associated with the four criteria (P1, P6, P7, and P10).

[Step B.1] Update initial matrix $X$ values $\left(x_{i j}\right)$ to normalized values $\left(r_{i j}\right)$ using Equation (8). The updated matrix is shown in Table T11.

[Steps B.2 and B.3] Update a normalized matrix $X$ values $\left(r_{i j}\right)$ to weighted normalized values $\left(v_{i j}\right)$ using Equation (9) as in Table T12. The cell values, denoted by $(\dagger)$, represent the ideal values and the ones, denoted by $(\dagger \dagger)$, represent the negative ideal values, determined by using Equation (10) and Equation (11), respectively. HIB indicates the preference as higher values being more preferred and LIB does for lower values being more preferred, respectively.

[Step B.4] The separation of each alternative criterion value from the ideal value and negative ideal value are calculated using Equations (12) and (13), respectively. Tables T13 and T14 show ideal solution separation values and negative ideal solution separation values.

[Step B.5] Relative closeness is calculated using Equation (14) and the alternatives are sorted from highest (most preferred option) to lowest (least preferred option), and presented in Table T15.

\subsection{Financial and operational performance results by TOPSIS}

Figure 2 presents the results of the five experiments using TOPSIS for the MCDM analysis. $A_{8}$ is the most preferred alternative across every experiment except for Experiment 4, where $A_{1}$ is most preferred. On the other hand, $A_{9}$ and $A_{3}$ are consistently the least preferred alternative. Most alternatives do not experience any significant preference level changes in terms of ranking position in the TOPSIS experiments. We observe rather a various magnitude of shifts in the TOPSIS preference values of alternatives across experiments. No clear trend emerges between the average TOPSIS preference scores (0.52-0.54) and the addition of airline operational measures in Experiments 1-5. Moreover, the ranges (0.39-0.41) and standard deviations $(0.13)$ of preference values between the first experiment and the remaining four experiments also indicate that there is no direct relation between these measurements and the number of criteria taken into consideration. This is likely due primarily to the subjective criteria weights assessed by a decision maker. To mitigate the degree of subjectiveness, next we consider using FAHP in assigning criteria weights and demonstrate a hybrid model combining FAHP and TOPSIS in Section 6. 


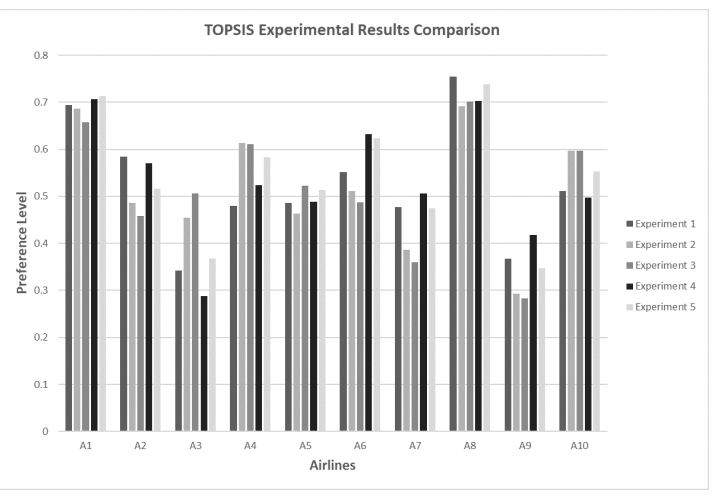

Fig. 2. TOPSIS experimental results

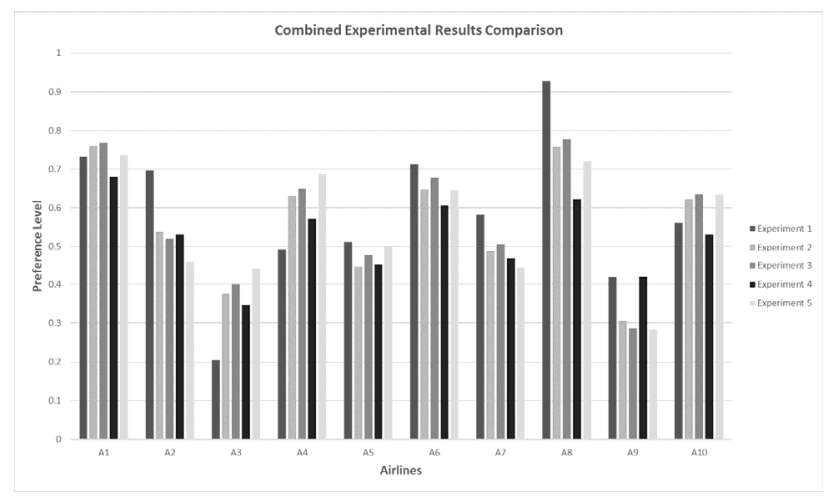

Fig. 3. Hybrid experimental results

\section{Experiments of hybrid model}

Similar to the cases presented in Sections 4 and 5, we conduct five experiments regarding the airline financial and operational performance evaluation using a hybrid of FAHP and TOPSIS. Table T16 shows the difference between the subjectively assigned weights and the FAHP-derived weights, each of which is used to compare the results from the TOPSIS and hybrid experiments, respectively. Moreover, the calculated weights reflect the significance of each criterion involved in the decision-making process. For example, Gross Margin is the most important factor in FAHP-derived weight followed by Total Asset Turnover, prioritizing their influence on financial performance. While the order of ranking among the alternatives of TOPSIS versus Hybrid remains the same in Table 3, the values between two adjacent ranks within Hybrid are more spread out on an average of 0.08 . With the hybrid result being taken as in Experiment 1, we discuss additional experiments and corresponding results in Section 6.1.

Table 3

Comparison of the results of TOPSIS and hybrid methods

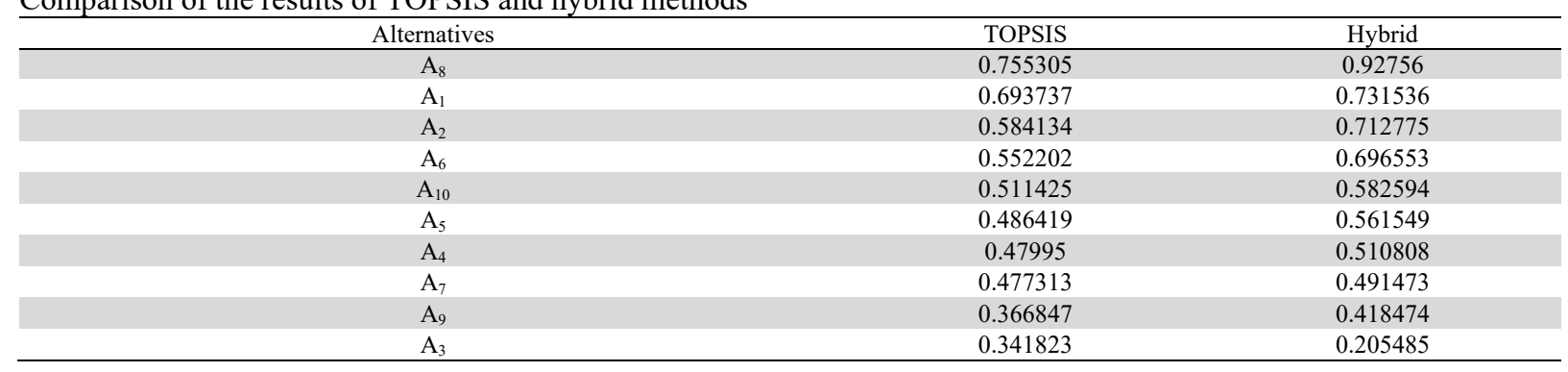

\subsection{Financial and operational performance results by a hybrid model}

Fig. 3 illustrates the results of the five experiments using a combined FAHP and TOPSIS method for the MCDM analysis. $A_{1}$ is the most preferred alternative in Experiments 2, 4, and 5 whereas $A_{8}$ is most preferred in Experiments 1 and 3 . On the other hand, $A_{3}$ and $A_{9}$ turn out to be two least preferred options. Across alternatives $A_{i}$, preference levels fluctuate more or less without a clear trend when additional operational criteria under D5 being considered. These changes, however, are not as significant as observed in the FAHP experiments. The ranges and standard deviations of the preference values also decrease by $14 \%$ and $6 \%$, respectively, amongst the experiments when the D5 criteria are included. It is worth noting that the preference values across the experiments resulted from the hybrid model are more variable with an $18 \%$ increase of standard deviations than those obtained by the application of TOPSIS alone.

\subsection{Hybrid model sensitivity analysis}

Next, we conduct sensitivity analyses to further investigate the hybrid model. Three scenarios in Experiment 4 (see Table 2) are developed to understand the effect of increasing airline operational criteria weights on preference levels. Experiment 4 is selected for sensitivity analysis since it involves the D5 criteria (P13, P14, and P16). Three scenarios are designed by decrementing $\mathrm{P} 10$ by $2 \%$ while $2 \%$ is incrementally added to $\mathrm{P} 13, \mathrm{P} 14$, and P16, one at a time in Scenarios $1-3$. For instance, in Scenario 1, only the weight distributions of criteria P10 and P13 are exchanged while other weights (P14 and P16) remain the same as baseline. Tables 4 and 5 summarizes the scenarios testing conducted in the sensitivity analysis. 
Table 4

Sensitivity analysis experiment designs.

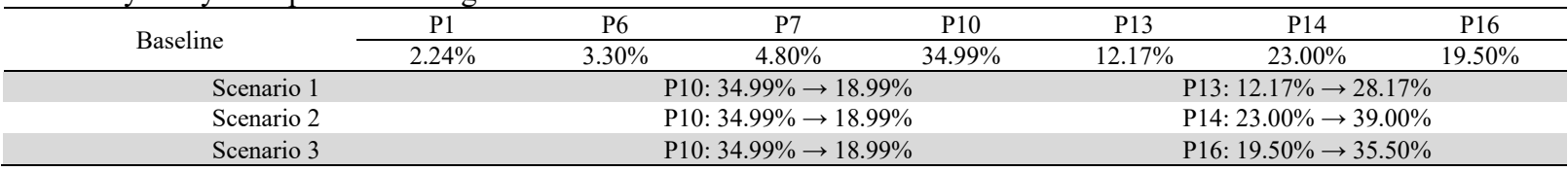

Table 5

Sensitivity analysis of incremental values.

\begin{tabular}{|c|c|c|c|c|c|c|c|c|}
\hline & Changed Criterion & Base Line & \multicolumn{6}{|c|}{ Incremental Values (2.0\% Increase or Decrease) } \\
\hline Scenarios 1-3 & $\mathrm{P} 10$ & $34.99 \%$ & $32.99 \%$ & $30.99 \%$ & & $22.99 \%$ & $20.99 \%$ & $18.99 \%$ \\
\hline Scenario 1 & P13 & $12.17 \%$ & $14.17 \%$ & $16.17 \%$ & . & $24.17 \%$ & $26.17 \%$ & $28.17 \%$ \\
\hline Scenario 2 & P14 & $23.00 \%$ & $25.00 \%$ & $27.00 \%$ & & $35.00 \%$ & $37.00 \%$ & $39.00 \%$ \\
\hline Scenario 3 & P16 & $19.50 \%$ & $21.50 \%$ & $23.50 \%$ & $\ldots$ & $31.50 \%$ & $33.50 \%$ & $35.50 \%$ \\
\hline
\end{tabular}

In Fig. 4, every alternative other than $A_{3}$ increases or decreases linearly in proportion to the incremental change of the weights associated with $\mathrm{P} 10$ and $\mathrm{P} 13$. Note that $A_{4}, A_{5}$, and $A_{9}$ increases preference values as more weights are added to P13. That is, these airlines perform better with respect to P13 than P10, indicating higher rates of load factor. Conversely, the other alternatives show descending trends as $\mathrm{P} 13$ weighs more relative to $\mathrm{P} 10$.

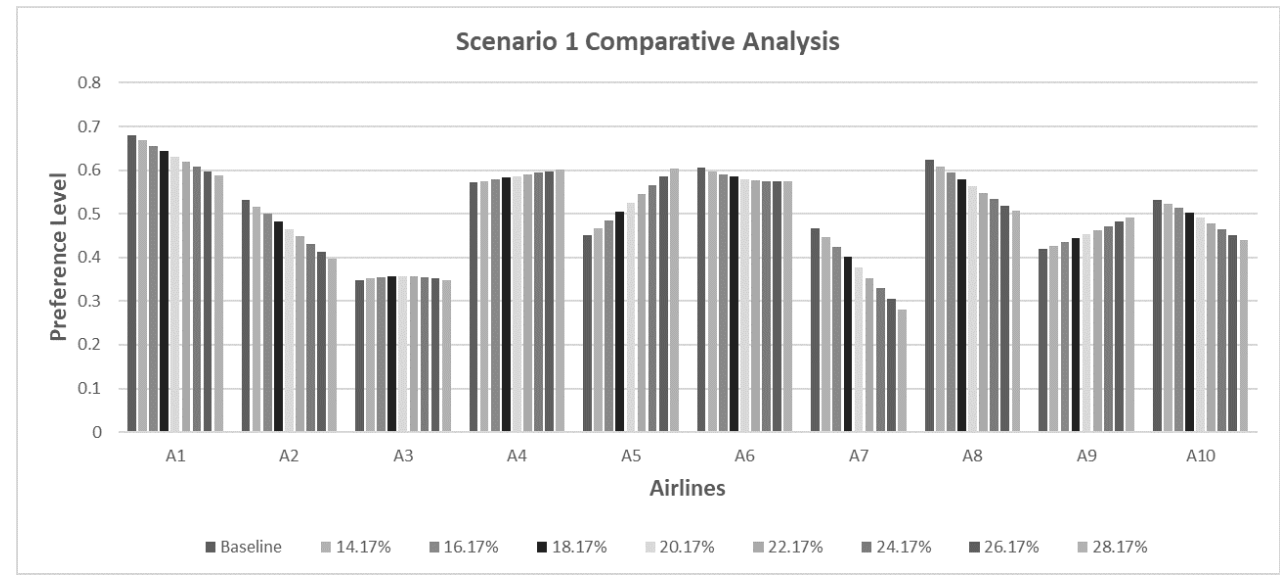

Fig. 4. Comparison results of Scenario 1

Fig. 5 shows the results of Scenarios 2 where every airline increases or decreases with the incremental change of the weights associated with $\mathrm{P} 10$ and P14. $A_{3}, A_{4}$, and $A_{10}$ trend increasing preferences as more weights are added to P14. The other alternatives, however, show a decreasing trend of preferences in response to an increase in P14 weight and a decrease in P10 weight. In particular, $A_{3}$ and $A_{7}$ are highly sensitive to the changes with the largest $(0.2)$ increase and decrease, respectively, in this scenario. This implies that RASM plays a significant role in the $A_{3}$ operation, but RASM is not the strong suit of $A_{7}$.

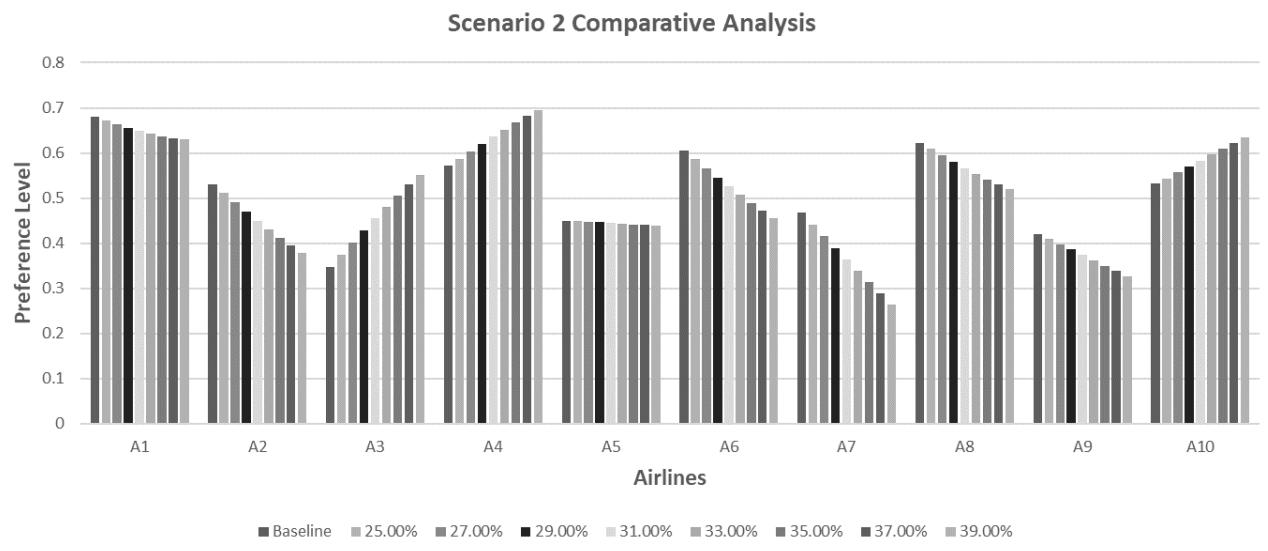

Fig. 5. Comparison results of Scenario 2 


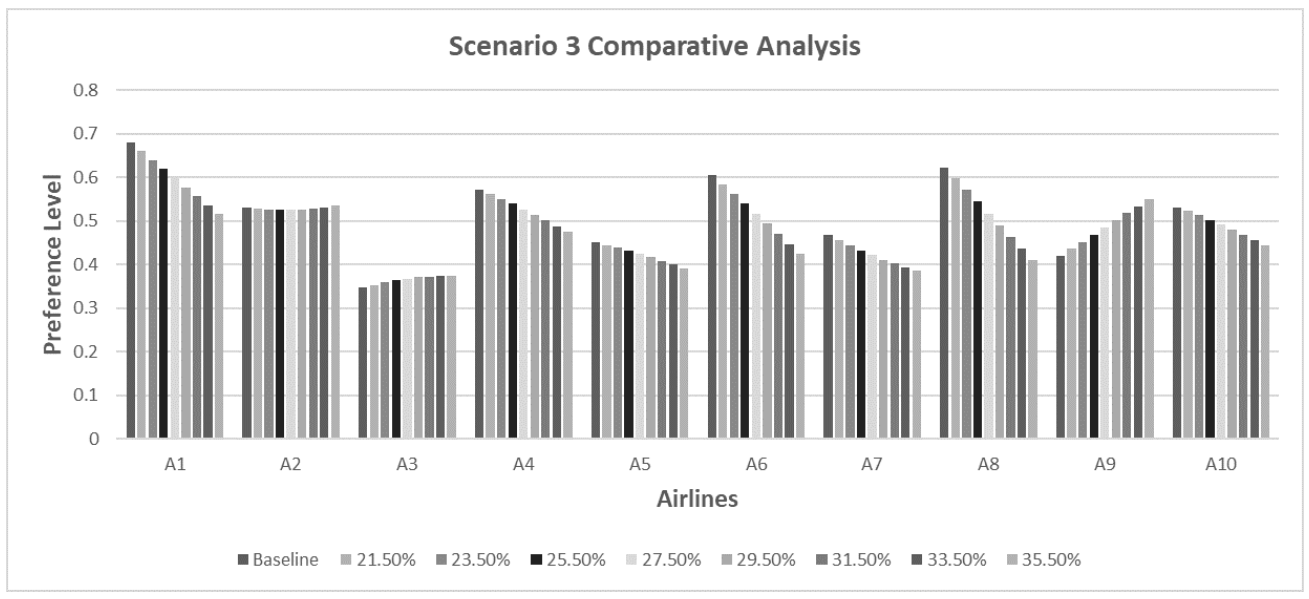

Fig. 6. Comparison results of Scenario 3

Fig. 6 shows that all airlines except $A_{2}$ increase or decrease proportionally with the incremental change of the weights associated with $\mathrm{P} 10$ and $\mathrm{P} 16 . A_{3}$ and $A_{9}$ are the only alternatives that increase preferences as more weights are added to P16, while the remaining alternatives indicate decreasing preference trends. Although operational criteria are regarded as the cause and financial criteria as the effect according to Pineda et al. (2018), our sensitivity analysis result asserts that the interrelation between financial and operational measures is complex and such one-dimensional logic is not applicable to all airlines.

\section{Conclusion}

This paper focuses on determining the competitiveness of airlines and evaluating their financial and operational performances based on a number of criteria. We demonstrate the applicability of FAHP, TOPSIS, and a hybrid of FAHP and TOPSIS to solve the complex airline MCDM problem. Without the use of these methods, ranking decision analyses regarding the preference of airlines would not be simple. While subjective elements play a role in the decision making process, some techniques including FAHP-derived weighting facilitate mitigating such subjective effects. Further, by judiciously distributing criteria weights, e.g., that are specific to the airline industry, our proposed model can capture preference values that reflect industry-specific and concurrent measures. We postulate that this modeling framework would aid airlines in better understanding the systematic influential relation structure among criteria, and prioritize them in critical financial and operational dimensions.

The experimental results of our hybrid FAHP-TOPSIS model demonstrates the efficacy of incorporating fuzzy values concerning influential weight criteria, and facilitates identifying strength and weakness in performance of airlines. The hybrid method enables findings that, after FAHP weight conversion, Gross Margin (P10) is most critical with the largest weight, followed by Total Asset Turnover (P7), while Debt Ratio (P1) and Time Interest Earned (P6) become less influential with their weights. In the sensitivity analyses, the proportion of weights between financial and operational criteria are redistributed. Although no direct (e.g., causal effect) relationship between them are identified over multiple scenarios, the preference levels of $A_{1}, A_{6}, A_{7}$, and $A_{8}$ decrease as more weights are transferred from P10 and assigned to Load Factor (P13), RASM (P14), or Passenger Yield (P16). These airlines usually achieve higher profit margins by operating their flights on a point-to-point network with low cost, while facing a barrier to a realization of economies of scale, e.g., large passenger enplanements and traffic consolidation.

While stacking up airlines against one another in terms of performance reveal competitive advantages or disadvantages, it also provides an opportunity to gauge, for example, asset liquidation, debt consolidation, and network restructuring, in particular, in readiness for post-pandemic recovery. In addition, making a decision to improve airline performance, regardless of whether the problem is associated with external (e.g., fuel cost) or internal (e.g., debt ratio) factors, poses inevitable challenges that need to be addressed and resolved in order to pave a viable path under adverse conditions. In the time of uncertainty rising amid the current pandemic-induced economic downturn, the airline industry landscape is likely to take a different shape on multiple fronts. For instance, most airlines have grounded a significant amount of their aircraft fleet and retired old fleet. A recovery process would involve downsizing the fleet and the demand for smaller aircraft will supposedly grow as airlines tap into this market, when the U.S. domestic travel slowly bounces back.

From the standpoint of airline financial performance, the turnover ratio (D3) is a better indicator than other measures to understand how airlines would quickly adapt and turn around under a new state of affairs. Obviously, load factor (P13) and passenger yield (P16) are the two measures most greatly affected by deflated air travel. However, both tend to be highly variable during unstable times, thus not necessarily a good barometer of airline recovery operations. On the other hand, route network structure along with its partnerships and alliances, although not considered in our study due to lack of data 
availability, are key measures to take into account from the point of airline operational performance. Continuing or cutting back service on which routes is an important decision for airlines to make in the light of a recovery process. In fact, more airline consolidation and mergers are likely to occur in the post-COVID era.

We note some limitations in this study. First, the computational results are attained according to the single period of 2018. If more recent data, particularly during or after the pandemic period, can be additionally obtained, our solution approach would shed different possible outcomes with regards to airline performance. Second, the proposed model can expand by developing a new MCDM ranking methodology or incorporating others in the literature such as ELECTRE (Elimination et Choice Translating Reality), PROMETHEE, MOORA, and DANP (Decision Making Trial and Evaluation Laboratory and the Analytical Network Process). These are the subjects of our ongoing study.

\section{References}

Akkaya, G., Turanoğlu, B., \& Öztaş, S. (2015). An integrated fuzzy AHP and fuzzy MOORA approach to the problem of industrial engineering sector choosing. Expert Systems with Applications, 42(24), 9565-9573.

Ayhan, M. B. (2013). A fuzzy AHP approach for supplier selection problem: A case study in a gear motor company. International Journal of Managing Value and Supply Chains, 4, 11-23.

Barrosa, C., \& Wanke, P. (2015). An analysis of African airlines efficiency with two-stage TOPSIS and neural networks. Journal of Air Transport Management, 44, 90-102.

Boutkhoum, O., Hanine, M., \& Bendarag, A. (2018). A comparative analysis approach based on fuzzy AHP, TOPSIS, and PROMETHEE for the selection problem of GSCM solutions. International Journal of Computer and Systems Engineering, 12(10), 859-870.

Brunelli, M. (2014). Introduction to the analytic hierarchy process (1st ed.). Springer.

Buckley, J. J. (1985). Fuzzy hierarchical analysis. Fuzzy Sets and Systems, 17(3), 233-247.

Bureau of Transportation Statistics. (2018). https://www.bts.gov/, accessed March 2018.

Chou, S. W., \& Chang, Y. C. (2008). The implementation factors that influence the ERP (enterprise resource planning) benefits. Decision Support Systems, 46(1), 149-157.

Ertuğrul, İ., \& Karakaşoğlu, N. (2009). Performance evaluation of Turkish cement firms with fuzzy analytic hierarchy process and TOPSIS methods. Expert Systems with Applications, 36(1), 702-715.

Feng, C. M., \& Wang, R. T. (2000). Performance evaluation for airlines including the consideration of financial ratios. Journal of Air Transport Management, 6(3), 133-142.

Garg, C. P. (2016). A robust hybrid decision model for evaluation and selection of the strategic alliance partner in the airline industry. Journal of Air Transport Management, 52, 55-66.

Gomes, L., Fernandes, J., \& Soares de Mello, J. (2014). A fuzzy stochastic approach to the multicriteria selection of an aircraft for regional chartering. Journal of Advanced Transportation, 48(3), 223-237.

IATA. (2020). The International Air Transport Association, https:/www.iata.org/en/pressroom/pr/2020-04-14-01/, accessed May 2020.

Jain, V., Sangaiah, A. K., Sakhuja, S., Thoduka, N., \& Aggarwal, R. (2018). Supplier selection using fuzzy AHP and TOPSIS: A case study in the Indian automotive industry. Neural Computing and Applications, 29(7), 555-564.

Kannan, D., Jabbour, A. B. L. D. S., \& Jabbour, C. J. C. (2014). Selecting green suppliers based on GSCM practices: Using fuzzy TOPSIS applied to a Brazilian electronics company. European Journal of Operational Research, 233(2), 432447.

Lima Jr., F. R., Osiro, L., \& Carpinetti, L. C. R. (2014). A comparison between fuzzy AHP and fuzzy TOPSIS methods to supplier selection. Applied Soft Computing, 21, 194-209.

Mergent Online. (2018). http://www.mergentonline.com, accessed March 2018.

Patil, S. K., \& Kant, R. (2014). A fuzzy AHP-TOPSIS framework for ranking the solutions of knowledge management adoption in supply chain to overcome its barriers. Expert Systems with Applications, 41(2), 679-693.

Pineda, P. J. G., Liou, J. J., Hsu, C. C., \& Chuang, Y. C. (2018). An integrated MCDM model for improving airline operational and financial performance. Journal of Air Transport Management, 68, 103-117.

Prascevic, N., \& Prascevic, Z. (2017). Application of fuzzy AHP for ranking and selection of alternatives in construction project management. Journal of Civil Engineering and Management, 23(8), 1123-1135.

Roy, T., \& Dutta, R. K. (2019). Integrated fuzzy AHP and fuzzy TOPSIS methods for multi-objective optimization of electro discharge machining process. Soft Computing, 23(13), 5053-5063.

Saaty, T. L. (2012). Decision making for leaders: the analytic hierarchy process for decisions in a complex world. (3rd ed.). RWS Publications.

Samanlioglu, F., Taskaya, Y. E., Gulen, U. C., \& Cokcan, O. (2018). A fuzzy AHP-TOPSIS-based group decision-making approach to IT personnel selection. International Journal of Fuzzy Systems, 20(5), 1576-1591.

Sirisawat, P., \& Kiatcharoenpol, T. (2018). Fuzzy AHP-TOPSIS approaches to prioritizing solutions for reverse logistics barriers. Computers \& Industrial Engineering, 117, 303-318.

Venkatesh, V. G., Zhang, A., Deakins, E., Luthra, S., \& Mangla, S. (2019). A fuzzy AHP-TOPSIS approach to supply partner selection in continuous aid humanitarian supply chains. Annals of Operations Research, 283(1), 1517-1550.

van Laarhoven, P. J. M., \& Pedrycz, W. (1983). A fuzzy extension of Saaty's priority theory. Fuzzy Sets and Systems, 11(13), 229-241. 
Wang, Y. J. (2008). Applying FMCDM to evaluate financial performance of domestic airlines in Taiwan. Expert Systems and Applications, 34(3), 1837-1845.

\section{Appendix}

Table T1

Fuzzy pairwise comparison (Ayhan, 2013)

\begin{tabular}{lll}
\hline Saaty Scale & Definition & Fuzzy Triangular Scale \\
\hline 1 & Equally Important & $(1,1,1)$ \\
3 & Weakly Important & $(2,3,4)$ \\
5 & Fairly Important & $(4,5,6)$ \\
7 & Strongly Important & $(6,7,8)$ \\
9 & Absolutely Important & $(9,9,9)$ \\
\hline 2 & & $(1,2,3)$ \\
4 & & $(3,4,5)$ \\
\hline 6 & The intermittent values between two adjacent scales & $(5,6,7)$ \\
\hline
\end{tabular}

\section{Table T2}

Saaty pairwise comparisons

\begin{tabular}{ccccc}
\hline Category & Criterion & P1 & P6 & P7 \\
\hline D1 & P1 & 1 & 0.333 & 0.2 \\
D2 & P6 & 3 & 1 & 0.125 \\
D3 & P7 & 5 & 3 & 0.167 \\
D4 & P10 & 8 & 6 & 1 \\
& & & & 3
\end{tabular}

Table T3

Fuzzy triangular comparisons

\begin{tabular}{ccccccccccccccc}
\hline Criterion & \multicolumn{3}{c}{ P1 } & & & P6 & & P7 & \\
\hline P1 & 1.00 & 1.00 & 1.00 & 0.25 & 0.33 & 0.50 & 0.16 & 0.20 & 0.25 & 0.11 & 0.13 & 0.14 \\
P6 & 2.00 & 3.00 & 4.00 & 1.00 & 1.00 & 1.00 & 0.25 & 0.33 & 0.50 & 0.14 & 0.16 & 0.20 \\
P7 & 4.00 & 5.00 & 6.00 & 2.00 & 3.00 & 4.00 & 1.00 & 1.00 & 1.00 & 0.25 & 0.33 & 0.50 \\
P10 & 7.00 & 8.00 & 9.00 & 5.00 & 6.00 & 7.00 & 2.00 & 3.00 & 4.00 & 1.00 & 1.00 & 1.00 \\
\hline
\end{tabular}

Table T4

Triangular geometric mean of each analyzed criterion

\begin{tabular}{ccccc}
\hline Category & Criterion & $\vec{r}_{l}$ & 0.302138 \\
D1 & P1 & 0.260847 & 0.638943 & 0.260847 \\
D2 & P6 & 0.516973 & 1.495349 & 1.516973 \\
D3 & P7 & 1.189207 & 3.464102 & 1.189207 \\
D4 & P10 & 2.892508 & 2.892508 \\
\hline
\end{tabular}

Table T5

Process of deriving fuzzy weights

\begin{tabular}{cccc}
\hline Criterion & & $\vec{r}_{l}$ & \\
\hline P1 & 0.260847 & 0.302138 & 0.638943 \\
P6 & 0.516973 & 1.495349 & 0.365555 \\
P7 & 1.189207 & 3.464102 & 1.86121 \\
\hline P10 & 2.892508 & 5.900531 & 3.984283 \\
\hline Pummation & 4.859535 & 0.169476 & 0.142728 \\
\hline
\end{tabular}

Table T6

Fuzzy weight distributions

\begin{tabular}{cccc}
\hline Category & Criterion & $\widetilde{W}_{l}$ & 0.051205 \\
\hline D1 & P1 & 0.03723 & 0.108286 \\
D2 & P6 & 0.073787 & 0.075224 \\
D3 & P7 & 0.169734 & 0.163652 \\
D4 & P10 & 0.412843 & 0.587083 \\
\hline
\end{tabular}

Table T7

Centre of area method results and final criterion weights

\begin{tabular}{cccc}
\hline Category & Criterion & $M_{i}$ & $N_{i}$ \\
\hline D1 & P1 & 0.054553 & 0.052198 \\
D2 & P6 & 0.115241 & 0.110266 \\
D3 & P7 & 0.26872 & 0.257119 \\
D4 & P10 & 0.606605 & 0.580417
\end{tabular}


Table T8

Alternative scores and criterion weights

\begin{tabular}{|c|c|c|c|c|c|c|c|c|c|c|c|}
\hline \multirow[b]{2}{*}{ Criteria } & \multirow[b]{2}{*}{ Weights } & \multicolumn{10}{|c|}{ Alternatives } \\
\hline & & $\mathrm{A}_{1}$ & $\mathrm{~A}_{2}$ & $\mathrm{~A}_{3}$ & $\mathrm{~A}_{4}$ & $\mathrm{~A}_{5}$ & $\mathrm{~A}_{6}$ & $\mathrm{~A}_{7}$ & $\mathrm{~A}_{8}$ & $\mathrm{~A}_{9}$ & $\mathrm{~A}_{10}$ \\
\hline $\mathrm{P} 1$ & 0.052198 & 0.083977 & 0.073665 & 0.01556 & 0.04985 & 0.05465 & 0.21698 & 0.06304 & 0.1495 & 0.25083 & 0.04191 \\
\hline P6 & 0.11026 & 0.275833 & 0.0587 & 0.03479 & 0.08064 & 0.05209 & 0.05561 & 0.02235 & 0.31019 & 0.06803 & 0.04173 \\
\hline P7 & 0.25711 & 0.030349 & 0.15803 & 0.06596 & 0.04606 & 0.23504 & 0.0345 & 0.0155 & 0.18085 & 0.07558 & 0.15803 \\
\hline $\mathrm{P} 10$ & 0.58041 & 0.165633 & 0.099142 & 0.01427 & 0.0526 & 0.0418 & 0.18501 & 0.12854 & 0.219866 & 0.0353 & 0.0577 \\
\hline
\end{tabular}

Table T9

Alternative weights multiplied by related criterion weights and summed

\begin{tabular}{cccccccccccc}
\hline & \multicolumn{7}{c}{ Alternatives } \\
\cline { 2 - 8 } Criteria & $\mathrm{A}_{1}$ & $\mathrm{~A}_{2}$ & $\mathrm{~A}_{3}$ & $\mathrm{~A}_{4}$ & $\mathrm{~A}_{5}$ & $\mathrm{~A}_{6}$ & $\mathrm{~A}_{7}$ & $\mathrm{~A}_{8}$ & $\mathrm{~A}_{9}$ & $\mathrm{~A}_{10}$ \\
\hline P1 & 0.004383417 & 0.003845 & 0.000812 & 0.002602 & 0.002853 & 0.011326 & 0.003291 & 0.007804 & 0.013093 & 0.002188 \\
P6 & 0.030415069 & 0.006473 & 0.003837 & 0.008892 & 0.005744 & 0.006133 & 0.002465 & 0.034204 & 0.007502 & 0.004602 \\
P7 & 0.007803374 & 0.040633 & 0.01696 & 0.011845 & 0.060434 & 0.008872 & 0.004006 & 0.046501 & 0.019433 & 0.040633 \\
P10 & 0.096136283 & 0.057544 & 0.008285 & 0.030558 & 0.024275 & 0.107385 & 0.074607 & 0.127614 & 0.020511 & 0.033504 \\
\hline Summation & 0.138738143 & 0.108494 & 0.029893 & 0.053897 & 0.093305 & 0.133716 & 0.084369 & 0.216122 & 0.060539 & 0.080927 \\
\hline
\end{tabular}

Table T10

Initial criteria weights and alternative scores in $X$

\begin{tabular}{|c|c|c|c|c|}
\hline Criteria Weight & $20.00 \%$ & $20.00 \%$ & $20.00 \%$ & $40.00 \%$ \\
\hline Alternative i & $\mathrm{P} 1$ & P6 & P7 & P10 \\
\hline $\mathrm{A}_{1}$ & 5.78 & 8.53 & 3.32 & 8.18 \\
\hline $\mathrm{A}_{2}$ & 5.55 & 3.38 & 7.97 & 6.63 \\
\hline $\mathrm{A}_{3}$ & 1.00 & 2.18 & 5.39 & 1.00 \\
\hline $\mathrm{A}_{4}$ & 4.60 & 4.18 & 4.35 & 5.09 \\
\hline $\mathrm{A}_{5}$ & 4.85 & 3.25 & 9.00 & 4.41 \\
\hline $\mathrm{A}_{6}$ & 8.58 & 3.35 & 3.58 & 8.35 \\
\hline $\mathrm{A}_{7}$ & 5.10 & 1.00 & 1.00 & 7.29 \\
\hline $\mathrm{A}_{8}$ & 7.26 & 9.00 & 8.23 & 9.00 \\
\hline $\mathrm{A}_{9}$ & 9.00 & 3.77 & 5.90 & 4.06 \\
\hline $\mathrm{A}_{10}$ & 4.08 & 2.60 & 7.97 & 5.22 \\
\hline
\end{tabular}

Table T11

Normalization of $X$

\begin{tabular}{|c|c|c|c|c|}
\hline Criteria Weight & $20.00 \%$ & $20.00 \%$ & $20.00 \%$ & $40.00 \%$ \\
\hline Alternative i & $\mathrm{P} 1$ & P6 & P7 & $\mathrm{P} 10$ \\
\hline $\mathrm{A}_{1}$ & 0.30 & 0.56 & 0.17 & 0.41 \\
\hline $\mathrm{A}_{2}$ & 0.29 & 0.22 & 0.41 & 0.33 \\
\hline $\mathrm{A}_{3}$ & 0.05 & 0.14 & 0.28 & 0.05 \\
\hline $\mathrm{A}_{4}$ & 0.24 & 0.27 & 0.22 & 0.25 \\
\hline $\mathrm{A}_{5}$ & 0.26 & 0.21 & 0.46 & 0.22 \\
\hline $\mathrm{A}_{6}$ & 0.45 & 0.22 & 0.18 & 0.41 \\
\hline $\mathrm{A}_{7}$ & 0.27 & 0.07 & 0.05 & 0.36 \\
\hline $\mathrm{A}_{8}$ & 0.38 & 0.59 & 0.42 & 0.45 \\
\hline $\mathrm{A}_{9}$ & 0.47 & 0.25 & 0.30 & 0.20 \\
\hline $\mathrm{A}_{10}$ & 0.22 & 0.17 & 0.41 & 0.26 \\
\hline
\end{tabular}

Table T12

Weighted normalization of $X$

\begin{tabular}{|c|c|c|c|c|}
\hline Weight & $20.00 \%$ & $20.00 \%$ & $20.00 \%$ & $40.00 \%$ \\
\hline Alternative $i \quad$ Criteria $j$ & $\mathrm{P} 1$ & P6 & P7 & $\mathrm{P} 10$ \\
\hline $\mathrm{A}_{1}$ & 0.06 & 0.11 & 0.03 & 0.16 \\
\hline $\mathrm{A}_{2}$ & 0.06 & 0.04 & 0.08 & 0.13 \\
\hline $\mathrm{A}_{3}$ & $0.01 \dagger$ & 0.03 & 0.06 & $0.02 \dagger \dagger$ \\
\hline $\mathrm{A}_{4}$ & 0.05 & 0.05 & 0.04 & 0.10 \\
\hline $\mathrm{A}_{5}$ & 0.05 & 0.04 & $0.09 \dagger$ & 0.09 \\
\hline $\mathrm{A}_{6}$ & 0.09 & 0.04 & 0.04 & 0.17 \\
\hline $\mathrm{A}_{7}$ & 0.05 & $0.01 \dagger \dagger$ & $0.01 \dagger \dagger$ & 0.14 \\
\hline $\mathrm{A}_{8}$ & 0.08 & $0.12 \dagger$ & 0.08 & $0.18 \dagger$ \\
\hline $\mathrm{A}_{9}$ & $0.09 \dagger \dagger$ & 0.05 & 0.06 & 0.08 \\
\hline $\mathrm{A}_{10}$ & 0.04 & 0.03 & 0.08 & 0.10 \\
\hline HIB/LIB & LIB & HIB & HIB & HIB \\
\hline
\end{tabular}


Table T13

Ideal solution separation measurements

\begin{tabular}{|c|c|c|c|c|c|c|c|}
\hline Alternative i & Criteria j & $\mathrm{P} 1$ & P6 & P7 & P10 & $\sum j$ & $\mathrm{Si}^{*}$ \\
\hline & $\mathrm{A}_{1}$ & 0.00254 & 0.00004 & 0.00336 & 0.00027 & 0.00621 & 0.078819 \\
\hline & $\mathrm{A}_{2}$ & 0.00230 & 0.00546 & 0.00011 & 0.00222 & 0.010089 & 0.100444 \\
\hline & $\mathrm{A}_{3}$ & 0.00000 & 0.00805 & 0.00136 & 0.02530 & 0.034706 & 0.186296 \\
\hline & $\mathrm{A}_{4}$ & 0.00144 & 0.00402 & 0.00225 & 0.00603 & 0.013739 & 0.117212 \\
\hline & $\mathrm{A}_{5}$ & 0.00165 & 0.00572 & 0.00000 & 0.00832 & 0.015685 & 0.125239 \\
\hline & $\mathrm{A}_{6}$ & 0.00638 & 0.00552 & 0.00306 & 0.00017 & 0.015134 & 0.123022 \\
\hline & $\mathrm{A}_{7}$ & 0.00187 & 0.01107 & 0.00668 & 0.00116 & 0.020777 & 0.144142 \\
\hline & $\mathrm{A}_{8}$ & 0.00436 & 0.00000 & 0.00006 & 0.00000 & 0.004424 & 0.066513 \\
\hline & $\mathrm{A}_{9}$ & 0.00711 & 0.00473 & 0.00100 & 0.00964 & 0.022476 & 0.149921 \\
\hline & $\mathrm{A}_{10}$ & 0.00105 & 0.00708 & 0.00011 & 0.00566 & 0.013899 & 0.117894 \\
\hline
\end{tabular}

Table T14

Negative ideal solution separation measurements

\begin{tabular}{|c|c|c|c|c|c|c|c|}
\hline Alternative $\mathrm{i}$ & Criteria j & $\mathrm{P} 1$ & P6 & P7 & $\mathrm{P} 10$ & $\sum j$ & $\mathrm{Si}^{\prime}$ \\
\hline & $\mathrm{A}_{1}$ & 0.00115 & 0.00981 & 0.00056 & 0.02035 & 0.03188 & 0.178538 \\
\hline & $\mathrm{A}_{2}$ & 0.00132 & 0.00098 & 0.00507 & 0.01253 & 0.019905 & 0.141085 \\
\hline & $\mathrm{A}_{3}$ & 0.00711 & 0.00024 & 0.00201 & 0.00000 & 0.009361 & 0.096752 \\
\hline & $\mathrm{A}_{4}$ & 0.00215 & 0.00175 & 0.00117 & 0.00662 & 0.011702 & 0.108174 \\
\hline & $\mathrm{A}_{5}$ & 0.00191 & 0.00088 & 0.00668 & 0.00460 & 0.01407 & 0.118616 \\
\hline & $\mathrm{A}_{6}$ & 0.00002 & 0.00096 & 0.00069 & 0.02134 & 0.023014 & 0.151705 \\
\hline & $\mathrm{A}_{7}$ & 0.00169 & 0.00000 & 0.00000 & 0.01564 & 0.017326 & 0.131629 \\
\hline & $\mathrm{A}_{8}$ & 0.00033 & 0.01107 & 0.00545 & 0.02530 & 0.042151 & 0.205306 \\
\hline & $\mathrm{A}_{9}$ & 0.00000 & 0.00133 & 0.00251 & 0.00371 & 0.007545 & 0.086864 \\
\hline & $\mathrm{A}_{10}$ & 0.00269 & 0.00045 & 0.00507 & 0.00703 & 0.015229 & 0.123407 \\
\hline
\end{tabular}

Table T15

Final sorted relative closeness values

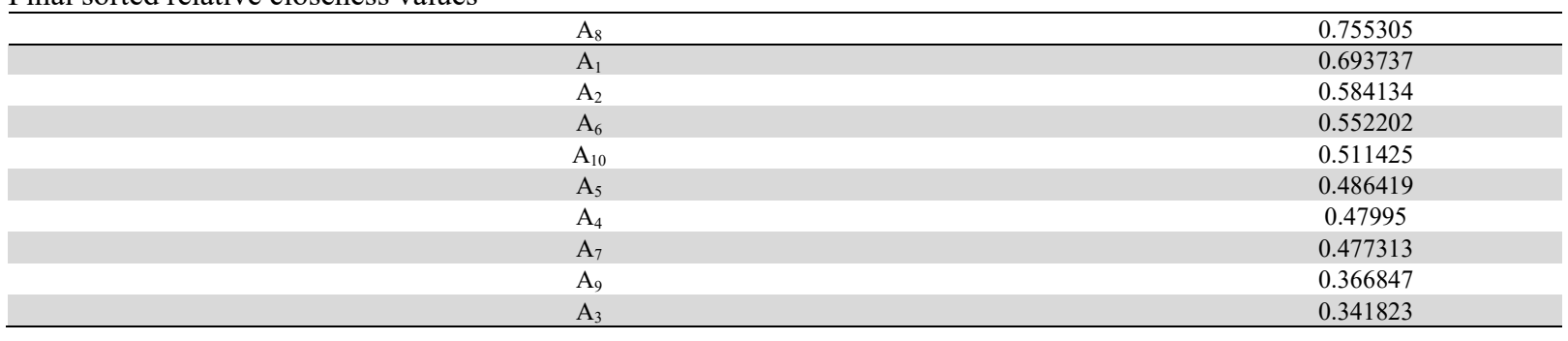

Table T16

Subjective vs. FAHP weight distributions of selected criteria.

\begin{tabular}{cccc}
\hline Criteria & P1 & P6 & P7 \\
\hline subjective weight & $20.00 \%$ & $20.00 \%$ & $20.00 \%$ \\
FAHP weight & $5.22 \%$ & $11.03 \%$ & $40.00 \%$ \\
\hline
\end{tabular}

